\title{
LEVANTAMENTO DE DADOS EPIDEMIOLÓGICOS RELATIVOS À OCORRENCIAS/ SURTOS DE DOENÇAS TRANSMITIDAS POR ALIMENTOS (DTAs) NO ESTADO DO PARANÁ - BRASIL, NO PERÍODO DE 1978 A 2000
}

\author{
Data research of foodborne diseases outbreaks from state of Paraná - Brazil, in the \\ period from 1978 to 2000
}

\author{
Gisele Van Amson ${ }^{1}$, Sônia Maria Chaves Haracemiv² ${ }^{2}$ Maria Lucia Masson ${ }^{3}$
}

\begin{abstract}
RESUMO
As doenças transmitidas por alimentos (DTAs) são causadas por agentes biológicos, químicos ou físicos, os quais penetram no organismo humano pela ingestão de água ou alimentos contaminados. Este trabalho tem como objetivo a realização de um levantamento dos dados disponíveis sobre surtos de origem alimentar ocorridos no Paraná, no período de 1978 a 2000 . O perfil epidemiológico das doenças transmitidas por alimentos no Brasil ainda é pouco conhecido, somente alguns estados e/ou municípios dispõem de estatísticas e levantamentos reais sobre os agentes etiológicos mais comuns, alimentos mais freqüentemente envolvidos e fatores contribuintes. Além disso, doenças transmitidas por alimentos nem sempre são oficialmente notificadas. No Paraná, dados obtidos oficialmente e disponíveis de surtos de DTAs apontam como agentes etiológicos mais freqüentes os de origem bacteriana, destacando-se Staphylococcus aureus e Salmonella sp. Verifica-se que os alimentos mais frequientemente associados aos surtos são de origem animal, sendo os domicílios os locais de ocorrência de maior incidência. O número de surtos de DTAs cresce a cada ano e grande parte dos consumidores desconhece os requisitos necessários para uma correta manipulação de alimentos, incluindo o armazenamento (locais, temperatura, tempo de armazenamento) e, principalmente os perigos que podem estar associados aos alimentos contaminados. Os gastos destinados ao tratamento das DTAs foram quantificados a partir de dados do Sistema Único de Saúde (SUS) e do Hospital de Clínicas/UFPR de Curitiba, mostrando-se elevados e reafirmando que a área de segurança alimentar necessita maior atenção.
\end{abstract}

Termos para indexação: Surtos, alimentos, Paraná.

\begin{abstract}
The foodborne diseases are caused by biological, chemical or physical agents. The aim of this work was the accomplishment of a research of the available data on outbreaks of foodborne diseases happened in State of Paraná, in the period from 1978 to 2000. Only little information exists on the epidemic profile of the foodborne diseases in Brazil. Besides, foodborne diseases are not always officially notified. In State of Paraná, official and available data of foodborne diseases outbreaks showed bacterial infections as more frequent etiological agents, standing out Staphylococcus aureus and Salmonella sp. It was verified that the more frequently foods associates to the outbreaks are of animal origin, being the homes the places of occurrence of larger incidence. The number of foodborne outbreaks grows every year and the consumers' great part ignores the necessary requirements for a correct food handling, including the storage and mainly, the dangers that can be associated to the contaminated foods. The patient-related costs were quantified starting from data of the Sistema Único de Saúde (SUS) and of the Hospital de Clínicas/UFPR from Curitiba, being shown high and reaffirming that food safety's area needs more attention.
\end{abstract}

Index terms: Outbreaks, food, Paraná.

(Recebido para publicação em 3 de dezembro de 2004 e aprovado em 16 de fevereiro de 2006)

\section{INTRODUÇÃO}

As doenças transmitidas por alimentos (DTAs) são causadas por agentes, os quais penetram no organismo humano através da ingestão de água ou alimentos contaminados. Estes agentes podem ser químicos, como pesticidas e metais tóxicos ou biológicos, como microrganismos patogênicos. Doenças causadas pela ingestão de plantas tóxicas e micotoxinas são também consideradas DTAs. Alimentos contaminados por agentes biológicos são, entretanto, a maior causa das enfermidades (NOTERMANS \& VERDEGAAL, 1992). Os alimentos contaminados aparentemente são normais, apresentam odor e sabor normais e, como o consumidor não está devidamente esclarecido ou consciente dos perigos envolvidos, não consegue identificar qual alimento poderia estar contaminado em suas últimas refeições. Sendo assim, torna-se difícil rastrear os alimentos responsáveis pelas toxinfecções ocorridas (FORSYTHE, 2000).

\footnotetext{
${ }^{1}$ Engenheira de Alimentos, mestranda do Programa de Pós-Graduação em Tecnologia de Alimentos - Universidade Federal do Paraná/UFPR - Cx. P. 19.011 81.531-990 - Curitiba, PR.

2Professora Doutora do Programa de Pós-Graduação em Tecnologia de Alimentos - Universidade Federal do Paraná/UFPR - Cx. P. 19.011 - 81.531-990 Curitiba, PR.

${ }^{3}$ Professora Doutora do Programa de Pós-Graduação em Tecnologia de Alimentos - Universidade Federal do Paraná/UFPR - Cx. P. 19.011 - 81.531-990 Curitiba, PR.
} 
Na descrição de um surto de DTA, alguns fatores devem ser considerados: a situação; o número de pessoas afetadas; o índice de ataque por idade, sexo e raça; o número de pessoas que não foram atingidas, o agente e o período de incubação; a natureza clínica da doença; o veículo alimentar e o modo de transmissão para os alimentos e para as vítimas (HOBBS \& ROBERTS, 1999). Muitos casos de enfermidades transmitidas por alimentos não são notificados, pois seus sintomas são geralmente parecidos com gripes ou discretas diarréias e vômitos. Dentre os sinais e sintomas mais comuns tem-se dor de estômago, náusea, vômitos, diarréia e febre por período prolongado (FORSYTHE, 2000).

O número de casos notificados pode ser definido como a ponta de um iceberg, comparando-se com o número real de casos (FORSYTHE, 2000). Um estudo realizado na Inglaterra em 1999 estimou a extensão de casos nãonotificados e constatou que, para cada caso notificado (detectado em laboratórios oficiais de vigilância), existem mais 136 casos na comunidade, como mostra a Figura 1 (WHEELER et al., 1999, citados por FORSYTHE, 2000).

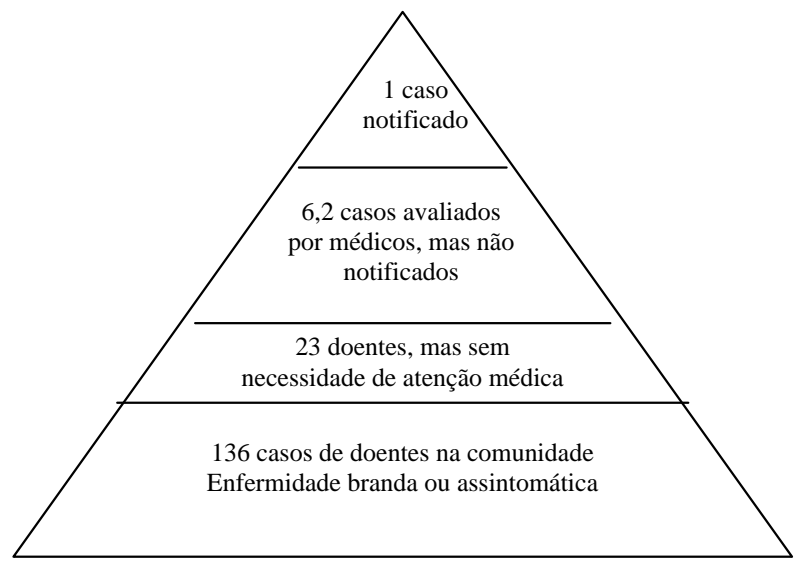

FIGURA 1 - Pirâmide que ilustra a relação entre casos notificados e não-notificados de enfermidades transmitidas por alimentos.

Fonte: Wheeler et al., citados por Forsythe (2000).

\section{MATERIAL E MÉTODOS}

O levantamento sobre a ocorrência de doenças transmitidas por alimentos no Estado do Paraná foi realizado a partir de dados disponibilizados pela Secretaria de Estado da Saúde do Paraná. Estes dados foram coletados através de boletins mensais procedentes de municípios paranaenses, no período de 1978 a 2000.
Informações adicionais fornecidas pelo Sistema Único de Saúde (SUS) e pelo Hospital de Clínicas de Curitiba foram utilizadas para complementar o levantamento.

\section{RESULTADOS E DISCUSSÃO}

\section{Perfil epidemiológico}

A epidemiologia é definida como o estudo das doenças que acometem uma população, sua frequiência de ocorrência, sua distribuição, suas causas e controle, assim como a sua relação com as doenças referentes a animais (HOBBS \& ROBERTS, 1999).

O perfil epidemiológico das doenças transmitidas por alimentos no Brasil ainda é pouco conhecido e carente, apenas alguns estados e/ ou municípios dispõem de estatísticas e dados sobre os agentes causadores de DTAs mais comuns, alimentos mais frequientemente envolvidos e fatores contribuintes.

No Paraná, dados disponíveis e coletados de surtos de DTAs apontam como agentes etiológicos mais freqüentes os de origem bacteriana, como mostra a Tabela 1. Os agentes etiológicos químicos mais comumente envolvidos em surtos são representados por animais ou vegetais tóxicos, produtos químicos tóxicos e aflatoxina (PARANÁ, 2003).

TABELA 1 - Número de surtos de DTAs, segundo categoria do agente etiológico, PR (1978 - 2000).

\begin{tabular}{lcc}
\hline $\begin{array}{l}\text { Categoria do } \\
\text { agente }\end{array}$ & $\begin{array}{c}\text { Número de } \\
\text { surtos }\end{array}$ & \% \\
\hline Bacterianos & 1195 & 59,8 \\
Químicos & 122 & 6,1 \\
Outras causas & 683 & 34,1 \\
Total & 2000 & 100,0
\end{tabular}

Fonte: Paraná (2003).

Nota - Outras causas: Desconhecimento do agente causal.

Dentre os agentes bacterianos, aqueles que estão relacionados e implicados com o maior número de surtos são: Staphylococcus aureus e Salmonella sp. Na Tabela 2, apresentam-se o número e a porcentagem de surtos em que estão envolvidos cada agente bacteriano.

Ciênc. agrotec., Lavras, v. 30, n. 6, p. 1139-1145, nov./dez., 2006 
TABELA 2 - Levantamento de DTAs, segundo agente bacteriano envolvido, PR (1978-2000).

\begin{tabular}{lcc}
\hline \multicolumn{1}{c}{ Categoria do agente } & Número de surtos & \% \\
\hline Staphylococcus aureus & 492 & 41,2 \\
Salmonella sp & 404 & 33,8 \\
Clostridium perfringens & 122 & 10,2 \\
Bacillus cereus & 75 & 6,3 \\
Escherichia coli & 66 & 5,5 \\
Shigella sp & 17 & 1,4 \\
Vibrio cholerae & 03 & 0,2 \\
Campylobacter sp & 01 & 0,1 \\
Outros & 15 & 1,3 \\
\hline Total & $\mathbf{1 1 9 5}$ & $\mathbf{1 0 0 , 0}$
\end{tabular}

Fonte: Paraná (2003).

O Staphylococcus aureus faz parte da flora normal de mucosas e pele e pode ser transmitido aos alimentos por contato direto ou indireto (através de fragmentos de pele e secreções do trato respiratório). Nos alimentos, podem se multiplicar e produzir enterotoxinas a partir de contagens de S. aureus em torno de $10^{6} \mathrm{UFC/g}$. Depois da ingestão da enterotoxina, uma intoxicação alimentar pode ocorrer, sendo o vômito o principal sinal (HOBBS \& ROBERTS, 1999; NOTERMANS \& VERDEGAAL, 1992). As condições que favorecem sua multiplicação e produção de toxinas em alimentos são: higiene pessoal precária, preparo de alimentos com muita antecedência, cocção ou aquecimento inadequado do alimento, uso prolongado de pratos aquecidos para servir os alimentos e refrigeração inadequada. Embora o $S$. aureus seja rapidamente destruído pela pasteurização e por processos de cozimento, sua toxina é mais resistente ao calor, sendo destruída gradualmente pela fervura em torno de, no mínimo, 30 minutos (HOBBS \& ROBERTS, 1999; SENAI, 2000). Desse modo, medidas preventivas devem estar relacionadas a higiene pessoal na manipulação, ao adequado preparo e armazenamento de alimentos.

A Salmonella pode ser encontrada no trato intestinal de mamíferos, aves, anfíbios e répteis. Alguns tipos de Salmonella podem causar infecções com sintomas clínicos bem definidos. A $S$. enteritidis, assim como a $S$. typhimurium, é invasiva e pode penetrar órgãos reprodutivos de aves, contaminando assim os ovos e vísceras. Alimentos como carne, leite cru e outros que possam ter contato com material fecal podem ser contaminados. Como a Salmonella pode se multiplicar facilmente em alimentos de origem animal e, sua dose infectante varia de 10 células a milhões delas, dependendo de fatores humanos e do tipo de alimento, fatores extrínsecos e intrínsecos, sua ausência em produtos alimentícios é exigida na maioria dos países (NOTERMANS \& VERDEGAAL, 1992). A prevenção consiste no aquecimento dos alimentos à temperatura de $65 \mathrm{a} 74^{\circ} \mathrm{C}$, manutenção dos mesmos em temperaturas abaixo de $5^{\circ} \mathrm{C}$, prevenção de contaminação cruzada pós-cocção e higiene pessoal de manipuladores (SENAI, 2000).

Dentre os surtos de salmonelose humana, o ovo pode destacar-se como um dos principais alimentos veiculadores. O fato de que ovos crus são utilizados, entre outros, para produção de maionese caseira, por exemplo, deve ser considerado. Pela Figura 2, apresentam-se o número de surtos de salmonelose e o número de surtos de salmonelose transmitida por ovos de 1993 a 2000, no Paraná.

Alimentos que freqüentemente estão associados a surtos são aqueles de origem animal. Isso porque os organismos que habitam os animais podem ser encontrados na carne crua após o abate e podem ser também transmitidos para outros alimentos. Outro fator a ser considerado é o de que esses alimentos representam excelentes meios para o crescimento bacteriano, devido à variedade de nutrientes, à alta atividade de água, à baixa acidez (pH entre 5,5 e 7,0) e, muitas vezes, serem estocados sem refrigeração (FORSYTHE, 2000; HOBBS \& ROBERTS, 1999). A proporção de surtos com relação aos alimentos envolvidos está representada na Figura 3. 


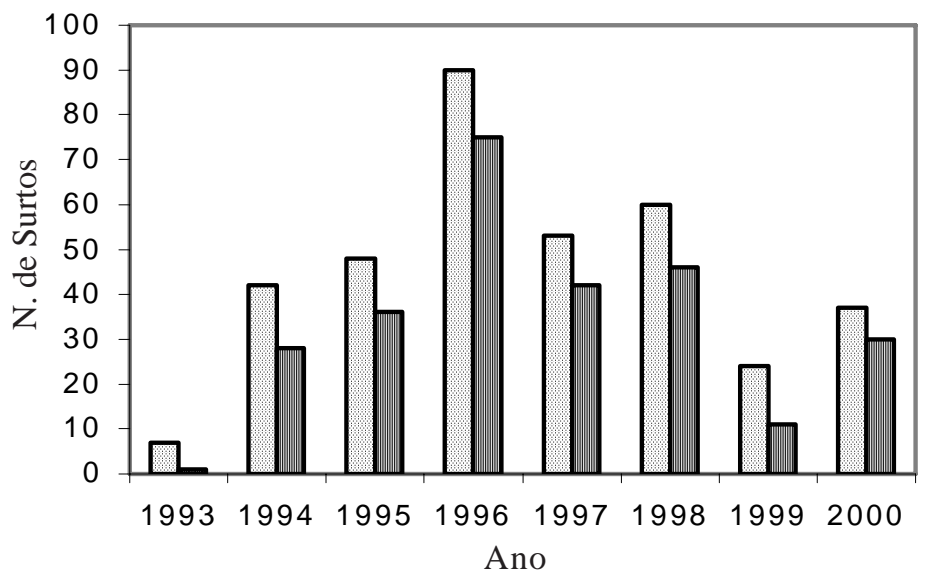

Surtos de Salmonelose

血 Surtos de Salmonelose transmitida por ovos

FIGURA 2 - Surtos de Salmonelose humana transmitida por ovos, em relação ao total de surtos de salmonelose, PR (1993-2000).

Fonte: Paraná (2003).

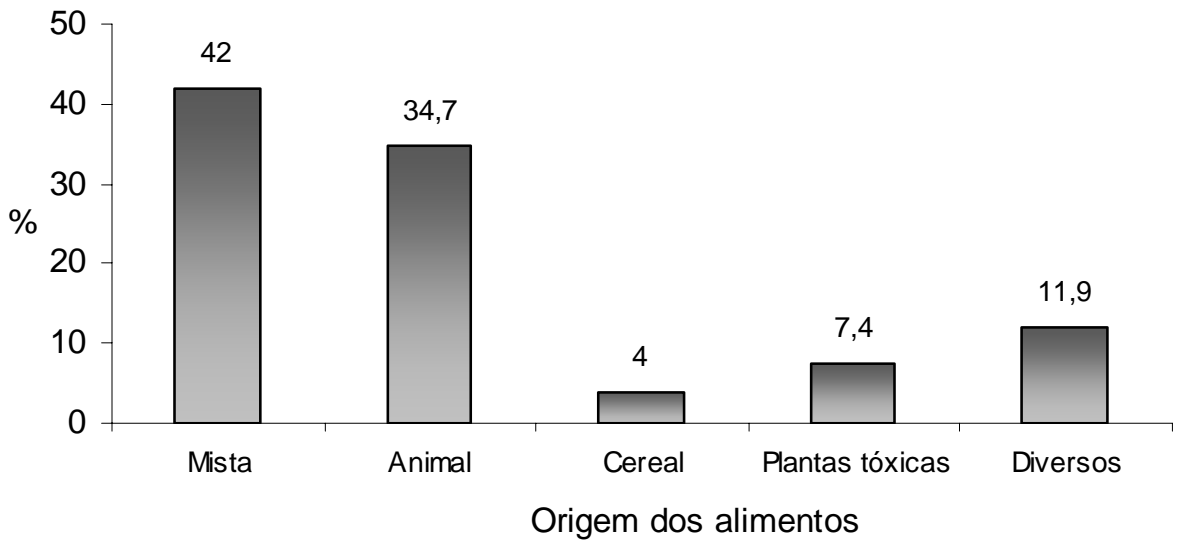

FIGURA 3 - Proporção de surtos de DTAs, segundo a origem dos alimentos envolvidos, PR (1978 - 2000).

Fonte: Paraná (2003).

Notas - "Mista" inclui matérias-primas de origem animal e vegetal (maionese, panqueca, bolo, farofa). "Diversas" inclui alimentos como refrescos e tubérculos.

Os domicílios representam o local de ocorrência de surtos de DTAs de maior incidência. A ausência de programas de educação em segurança alimentar dirigidos à população certamente está relacionada com este dado estatístico. Grande parte dos consumidores desconhece os requisitos necessários para uma correta manipulação de alimentos, incluindo o armazenamento (locais, temperatura, tempo de armazenamento) e, principalmente, desconhece os perigos que podem estar associados a alimentos contaminados. Na Figura 4, apresenta-se o percentual de surtos de DTAs, segundo o local de ocorrência.

A partir das estatísticas, pode-se concluir que, ao invés de diminuir, os surtos de enfermidades de origem alimentar têm aumentado. Na Figura 5, apresenta-se o número de surtos provocados por doenças transmitidas por alimentos no Paraná, entre 1978 e 2000. 


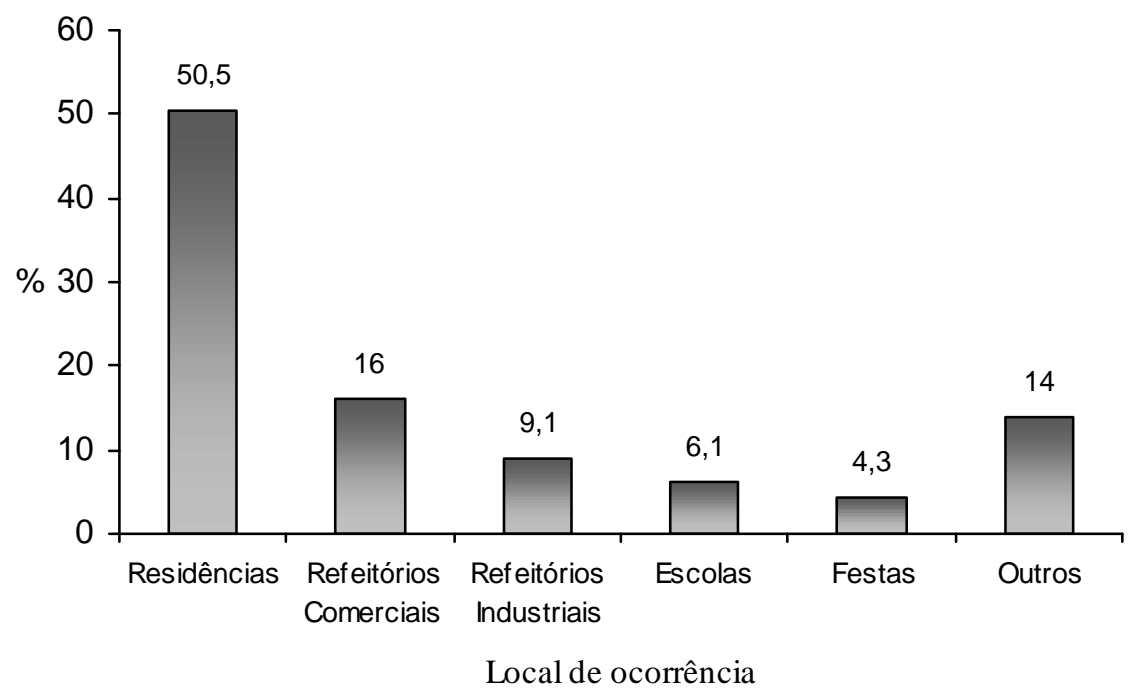

FIGURA 4 - Percentual de surtos de DTAs, segundo local de ocorrência, PR (1978 - 2000). Fonte: Paraná (2003).

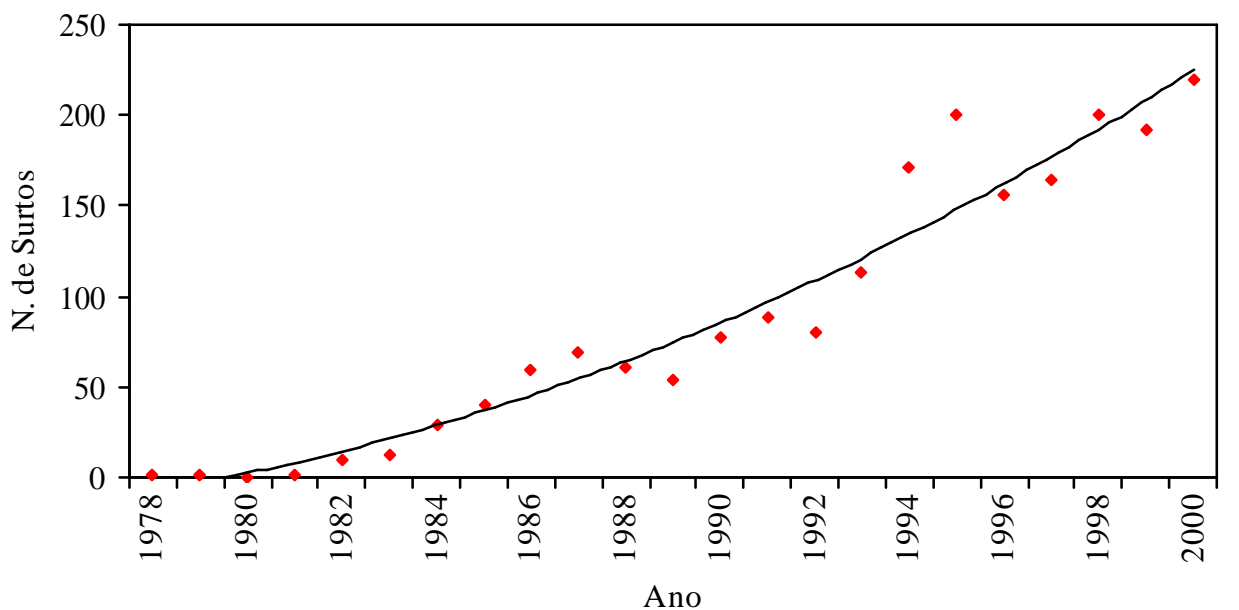

FIGURA 5 - Número de surtos de DTAs, segundo o ano de ocorrência, PR (1978 - 2000)

Fonte: Paraná (2003).

Melhorias nos métodos de processamento dos alimentos, como a adoção e aplicação de programas de Boas Práticas de Fabricação (BPF), e a educação dos responsáveis pelo fornecimento de alimentos, com certeza reduziriam a incidência das doenças de origem alimentar. É essencial que se conheça as causas das doenças, agentes bacterianos, locais onde os incidentes ocorreram e quais fatores contribuíram para os incidentes. Muitas práticas inadequadas que ocorrem durante o processamento permitem as contaminações, a sobrevivência e a multiplicação de microrganismos patogênicos. Um estudo destes fatores fornece dados que podem ser utilizados na educação das pessoas envolvidas na produção de alimentos (FORSYTHE, 2000; HOBBS \& ROBERTS, 1999).

$\mathrm{Na}$ Tabela 3, apresentam-se os fatores contribuintes associados aos surtos de DTAs no Paraná, reafirmando que, se fossem oferecidas orientações aos manipuladores a respeito da correta manipulação de alimentos e dos perigos associados a alimentos contaminados, o número de surtos poderia certamente ser reduzido. A diminuição do número de surtos, em consequiência, representaria uma diminuição de gastos com medicamentos, internações e perdas de dias de trabalho, entre outras perdas não só econômicas como também sociais. 
TABELA 3 - Fatores contribuintes associados aos surtos de DTAs, PR (1978 - 2000).

\begin{tabular}{lc}
\hline Fatores contribuintes & $\%$ \\
\hline RELATIVOS À CONTAMINAÇÃO (MICROBIOLÓGICA OU QUÍMICA) & \\
Matéria-prima contaminada (microbiológica) & 75,8 \\
Manipuladores contaminados & 44,2 \\
Equipamentos contaminados & 34 \\
Contaminação cruzada & 28,4 \\
Alimento tóxico & 5,1 \\
Contaminação química & 1,4
\end{tabular}

RELATIVOS À SOBREVIVÊNCIA MICROBIOLÓGICA

Processamento inadequado pelo calor (tempo/ temperatura) 38,3

Reaquecimento inadequado $\quad 23,4$

RELATIVOS À MULTIPLICAÇÃO MICROBIOLÓGICA

Conservação inadequada pelo frio $\quad 88,5$

Tempo muito longo entre preparo e consumo $\quad 90,6$

Fonte: Paraná (2003).

Nota - A soma dos percentuais excede $100 \%$ porque diversos fatores contribuíram para cada surto.

Gastos relacionados a doenças transmitidas por alimentos

Quantificações a respeito dos gastos e dos impactos econômicos causados pelas DTAs são praticamente inexistentes mas, suficientes para revelar que essas doenças representam um enorme fardo para a economia. Os custos com doenças transmitidas por alimentos incluem diminuição na renda pessoal devido à perda de dias de trabalho, custos com cuidados médicos, diminuição de produtividade, custos relacionados à investigação de surtos, fechamento de empresas e diminuição nas vendas quando consumidores evitam comprar determinados produtos, entre outros.

Dados do Sistema Único de Saúde (SUS) revelam que no Paraná, no ano de 2000, o custo médio por internação foi de R \$ 471,59. Neste mesmo ano, aconteceram 219 surtos de DTAs, 1000 pessoas foram hospitalizadas e, estima-se que 8.663 ficaram doentes. Dados do Hospital de Clínicas de Curitiba (BRASIL, 2003) mostram que pacientes que são internados devido à enfermidades de origem alimentar ficam internados em média 4 dias, oferecendo um custo total médio de $\mathrm{R} \$ 1.870,00$, incluindo o número de diárias, honorários, materiais, medicamentos e exames.
Considerando as informações citadas, pode-se estimar que no ano de 2000 foram gastos pelo governo R \$ 1.870.000,00 somente em internações devido às doenças transmitidas por alimentos (BRASIL, 2003).

O gasto médio do SUS, com atendimento ambulatorial foi estimado em $\mathrm{R} \$ 3,26$ por doente, no ano de 2000. Como não existem dados sobre o número de pessoas que procuram atendimento ambulatorial devido à ingestão de alimentos contaminados, não é possível estimar o gasto com esse tipo de atendimento (BRASIL, 2003).

\section{CONCLUSÃO}

A necessidade de maior atenção na área de segurança alimentar é evidente. Melhorias nos métodos de processamento dos alimentos e a conscientização a respeito de segurança alimentar de todos os envolvidos na cadeia de produção de alimentos, com certeza reduziriam a incidência das doenças de origem alimentar (DTAs). Muitas práticas inadequadas que ocorrem durante o processamento, permitem as contaminações, pela sobrevivência e pela multiplicação de microrganismos patogênicos nos alimentos.

Ciênc. agrotec., Lavras, v. 30, n. 6, p. 1139-1145, nov./dez., 2006 
A implantação de programas de Boas Práticas de Fabricação (BPF) pode vir a promover a segurança alimentar aos consumidores, de modo eficaz e eficiente no controle das DTAs.

A deficitária cobertura dos serviços oficiais da Vigilância Sanitária de Alimentos, a ausência de notificação, a falta ou baixa forma de investigação dos surtos e a carência de informações aos consumidores são fatores que potencializam o aumento gradativo e ocasional da incidência dos surtos ou ocorrência das DTAs no País.

Considerando que $50,5 \%$ dos surtos de DTAs no Estado do Paraná, no período de 1978 a 2000, ocorreram em domicilios, planos de orientação e educação em segurança alimentar destinados aos consumidores, deveriam ser elaborados e implantados pelas Secretarias de Saúde, através de programas como, por exemplo, o Programa da Saúde da Família (PSF).

\section{AGRADECIMENTOS}

À CAPES (Coordenação de Aperfeiçoamento de Pessoal de Nível Superior), ao CNPq e ao projeto MESA, pelo financiamento da pesquisa de mestrado.

\section{REFERÊNCIAS BIBLIOGRÁFICAS}

BRASIL. Ministério da Saúde. Sistema de informações hospitalares do SUS. Disponível em: <http:// tabnet.datasus.gov.br/tabnet/tabnet.htm>i Acesso em: 20 jul. 2003 .

FORSYTHE, S. J. Microbiologia da segurança alimentar. Porto Alegre: Artmed, 2000. 424 p.

HOBBS, B. C.; ROBERTS, D. Toxinfecções e controle higiênicosanitário de alimentos. São Paulo: Varela, 1999. 376 p.

NOTERMANS, S.; VERDEGAAL, A. H. Existing and emergin foodborne diseases. International Journal of Food Microbiology, Amsterdam, v. 15, p. 197-205, 1992.

PARANÁ. Secretaria de Estado da Saúde do Paraná. Surto alimentar. Disponível em: ২http://www.saude.pr.gov.brh 'CSA/Surto_alimentar/index.htmp. Acesso em: 9 jun. 2003.

SENAI. Elementos de apoio para o sistema APPCC. 2. ed. Brasília, DF: SENAI/DN, 2000. 361 p. 